\title{
MONITORING AND ASSESSMENT OF ROAD CRACKS AND POTHOLES USING DIGITAL CLOSE RANGE PHOTOGRAMMETRY 3D RECONSTRUCTION TECHNIQUE
}

\author{
Hossam El-Din Fawzy* \\ Associate Professor, Civil Engineering Department, Faculty of Engineering, \\ Kafr El-Sheikh University, Kafr El-Sheikh, Egypt \\ Essam Sharaf El Din \\ Assistant Professor, Tanta University, Faculty of Engineering, \\ Public Works Engineering Department, Gharbeya, Egypt
}

\begin{abstract}
Designing roads and pavements is essential due to their role in transportation and communication infrastructure facilities in modern urban communities. Hence, it is crucial to evaluate the pavement durability conditions under the daily normal use of road validity. Monitoring/recording distortions of road surfaces, such as cracks and potholes, is the key factor of observing the surface evolution prior to launching the maintenance operation. One of the most recent technologies is the "Digital Close Range Photogrammetry" (DCRP), which is considered as an appropriate method for digitizing textured surfaces. In this research study, the obtained results showed a monitoring accuracy of less than a millimeter, which can lead to achieving the highest representation of the observed road surface without in situ (physical) measurements. Four to eight digital oriented stereo-images were found very sufficient to produce three-dimensional smart point cloud, as an application of the Scale Invariant Feature Transform (SIFT) algorithm. Five random pothole samples were chosen through a particular road and a longitudinal crack. Their severity levels were assessed through the photogrammetric technique, and an ortho photo, contour map, Digital Surface Model, and Digital Elevation Model were developed.
\end{abstract}

Keywords: Digital Close Range Photogrammetry, Monitoring, Road cracks, Camera calibration.

Cite this Article: Hossam El-Din Fawzy and Essam Sharaf El Din, Monitoring and Assessment of Road Cracks and Potholes using Digital Close Range Photogrammetry 3D Reconstruction Technique. International Journal of Civil Engineering and Technology 11(1), 2020, 119-128.

http://iaeme.com/Home/issue/IJCIET?Volume=11\&Issue=1 


\section{INTRODUCTION}

Globally, authorities are concerned about the road pavement network design and maintenance, which may occupy a considerable amount of national income to facilitate the transportation process between smart cities in order to enhance both social and economic development [1]. This keeps the road network in good durability condition, which can reduce the delay caused by crowding due to the presence of potholes and cracks that can lead to accidents $[2,3]$. Classification of the road network condition can be assessed using the visual scheduled observations that notice the number of potholes, crack length and type, and lane grooves, which are considered as remarkable indicators of the overall condition of a road [4]. Digital Close Range Photogrammetry (DCRP) is a technology that can be applied to different applications and fields, such as architectural photogrammetry, engineering photogrammetry, industrial photogrammetry, multi-media photogrammetry, etc. [5]. DCRP stores and manipulates digital images to create digital models that present the real captured objectives in order to identify the object geometry, such as length, area, and size [6].

In this study, the proposed photogrammetric approach uses the digital Photomodeler UAS and SURFER 16 software's to generate smart point mesh from the stereo overlapped images through the algorithm of edge detection mode of Scale Invariant Feature Transform (SIFT) [7]. Almost all of previous studies present the DCRP technique as a practical application of pavement monitoring, which can show some advantages of real-time acquisition with acceptable accuracy assessment [8, 9]. Therefore, as shown in Fig.1, a group of five potholes and one crack was selected to be digitally monitored and geometrically analyzed through the following workflow.

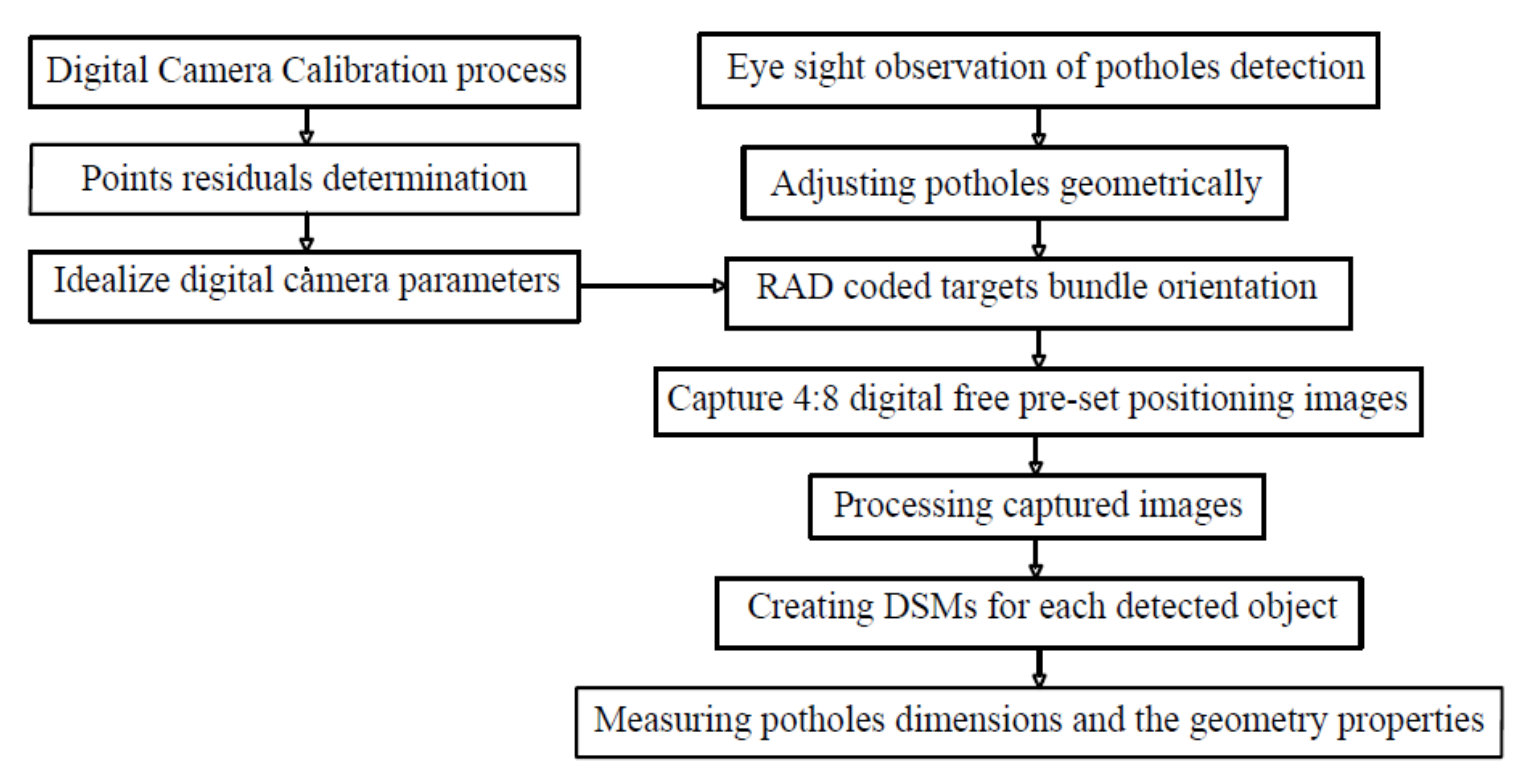

Figure 1 Workflow of the proposed study

\section{MATERIAL AND METHODS}

\subsection{Digital Camera Calibration}

The photogrammetric three-dimensional coordinates are calculated using the co-linearity equation, which simply develops the mathematical relation between World Coordinate System (WCS) and Image Coordinate System (ICS). All captured image points and the camera projective center are in a linear relation [10]. Each considerable point should be 
captured within at least nine images; hence, all points could be measured from the 3D monitoring, which is automatically manipulated by the profesional photogrammetric software (PhotoModeler UAS) [11]. The proposed method uses the Direct Linear Transform (DLT) to link the two-dimensional coordinates (ICS) to the corresponding object coordinates (WCS). The DLT between a point $(X, Y, Z)$ in the object space and the corresponding point in the image space $(\mathrm{x}, \mathrm{y})$ can be modeled using two linear fractional equations from a single calibration sheet printed on an A4 paper with 96 contrasted points and 4 Ground Control Points (GCPs), as shown in Fig.2.

The GCP resides on the bottom left corner is considered as the origin point $(0,0,0)$. All sheet points have $\mathrm{Z}$ value $=0$ and $\mathrm{X}, \mathrm{Y}$ values are measured from the software. Three digital images captured by a digital mobile phone camera, (Microsoft Lumia 640 XL, 13 MP, f = $3.7 \mathrm{~mm}$, and a constant focal length (1/3 inch sensor size)), which is used to carry out all the mentioned experiments in 0,90 , and 180 degrees around the orientation of the camera lens of each edge of the 3 sides of the sheet. Therefore, the total captured images $=9$ ( at least 9 images are needed to determine the lens unknown radial distortion values $\left(P_{1}, P_{2}, k_{1}, k_{2}, k_{3}\right)$ [12] with the camera format size and the image orientation angles Fig.3, 4, and 5 and table 1.

$$
\begin{aligned}
& \Delta x=x^{-}\left(k_{1} s^{2}+k_{2} s^{4}+k_{3} s^{6}\right)+P_{1}\left(s^{2}+2 x^{-2}\right)+2 P_{2} x^{-} y^{-} \\
& \Delta y=y^{-}\left(k_{1} s^{2}+k_{2} s^{4}+k_{3} s^{6}\right)+2 P_{1} x^{-} y^{-}+2 P_{2}\left(s^{2}+2 y^{-}\right)
\end{aligned}
$$

Where:

$$
\begin{aligned}
& x^{-}=x-x_{o} \\
& y^{-}=y-y_{o} \\
& s^{2}=\left(x-x_{o}\right)^{2}+\left(y-y_{o}\right)^{2}
\end{aligned}
$$

$\Delta \mathrm{x}, \Delta \mathrm{y}$ are systematic lens deformations of a digital image

$P_{1}, P_{2}$ are the two asymmetric parameters of decentring distortion

$k_{1}, k_{2}, k_{3}$ are the three radial distortion symmetric parameters,

$s$ is the radial distance of the image, and

$\mathrm{O}$ is the principal point.

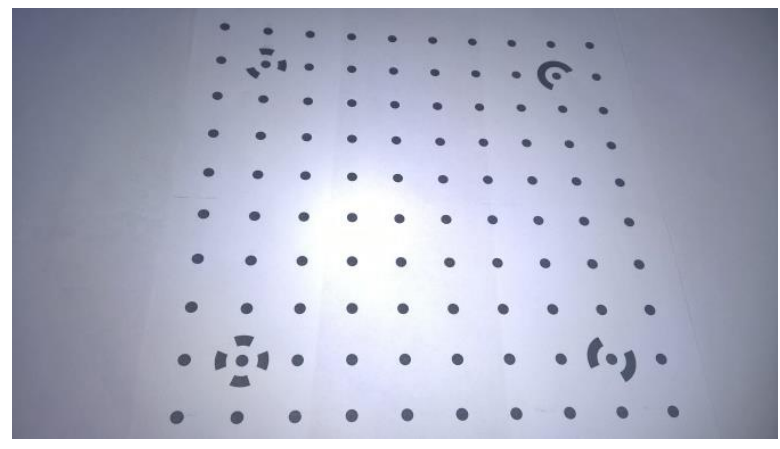

Figure 2 A4 camera calibration sheet model

\subsection{Eye Sight Observation for Potholes Detection}

Monitoring pavement distortions are based on direct observations and time inspection to record and create the necessary statistics and reports, which can describe the state of the targeted pavement. One of the fastest methods is the direct eye sight observation. One longitudinal crack and four potholes, positioned at $31^{\circ} 66^{\prime} 2.50^{\prime \prime} \mathrm{N}, 30^{\circ} 57^{\prime} 3.04 " \mathrm{E}$, at the newly paved road in front of Kafr El-Sheikh University are monitored. The main cause of the presence of these distortions is the daily use of the pavement and the fluctuation dynamic loads of vehicle tires (Fig.6). All potholes were cleaned to be digitally captured in order to 
create the 3D triangulation smart point cloud that describes the nature structure features of each pothole. Spatial information, such as volume, length, and width were measured to predict the necessary maintenance quantities.

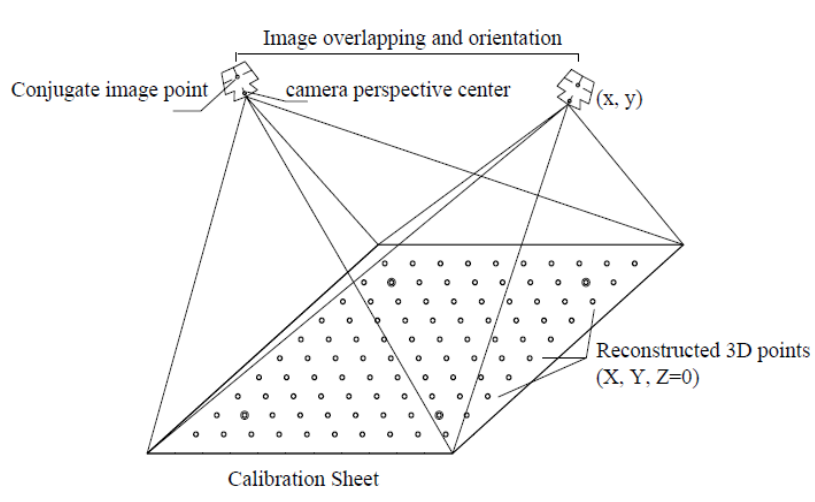

(a)

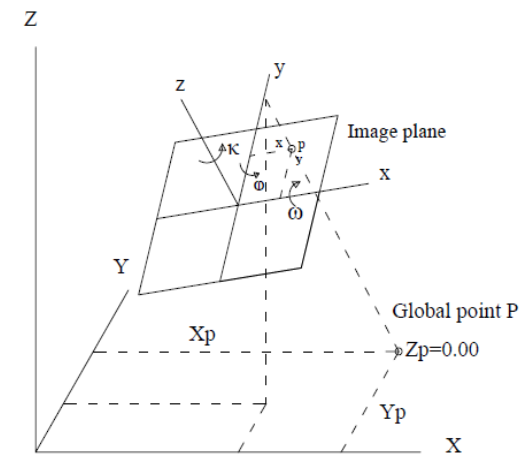

(b)

Figure 3 Stereo image orientation (a). Collinearity principle parameters (b)

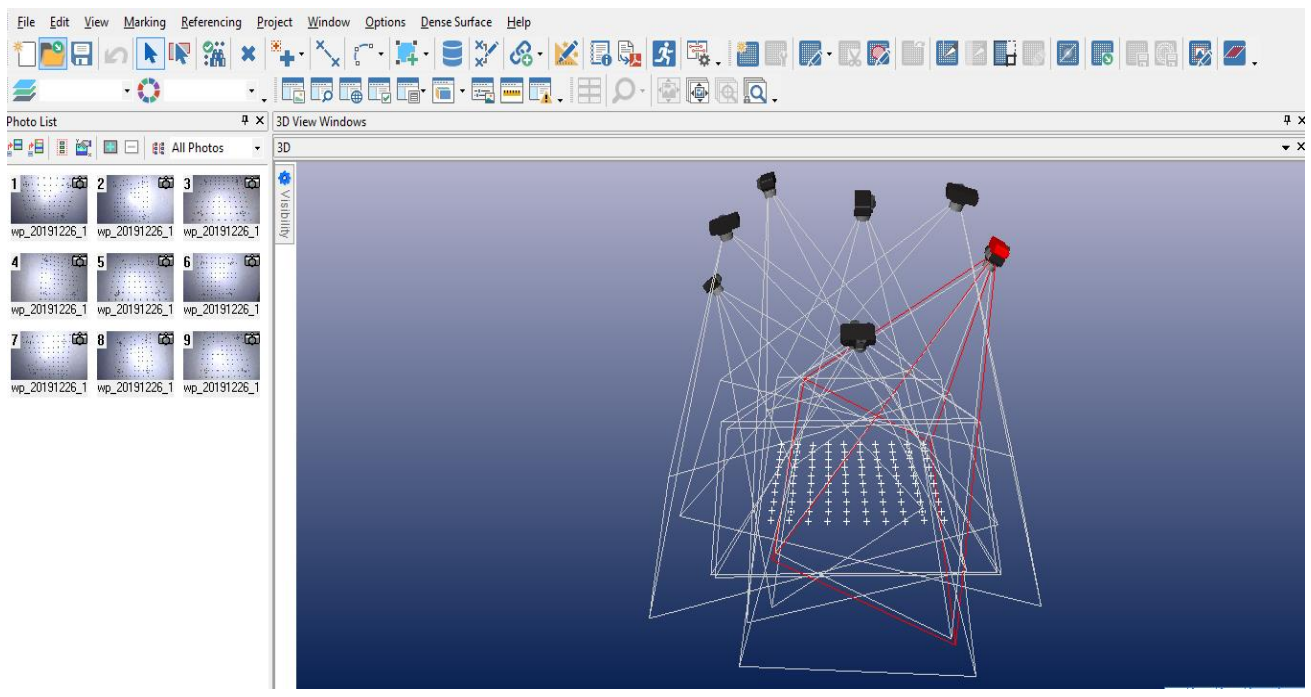

Figure 4 Camera calibration (images plans overlapping)

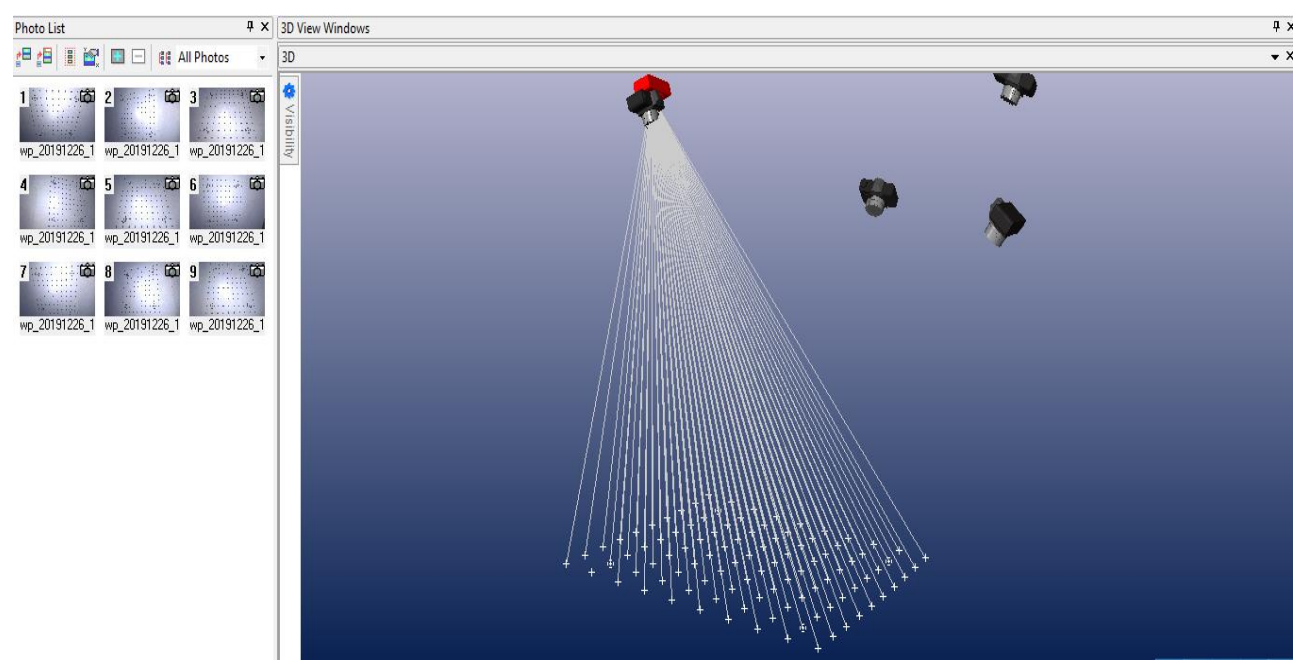

Figure 5 Applying collinearity for camera calibration (automatic point detection) 


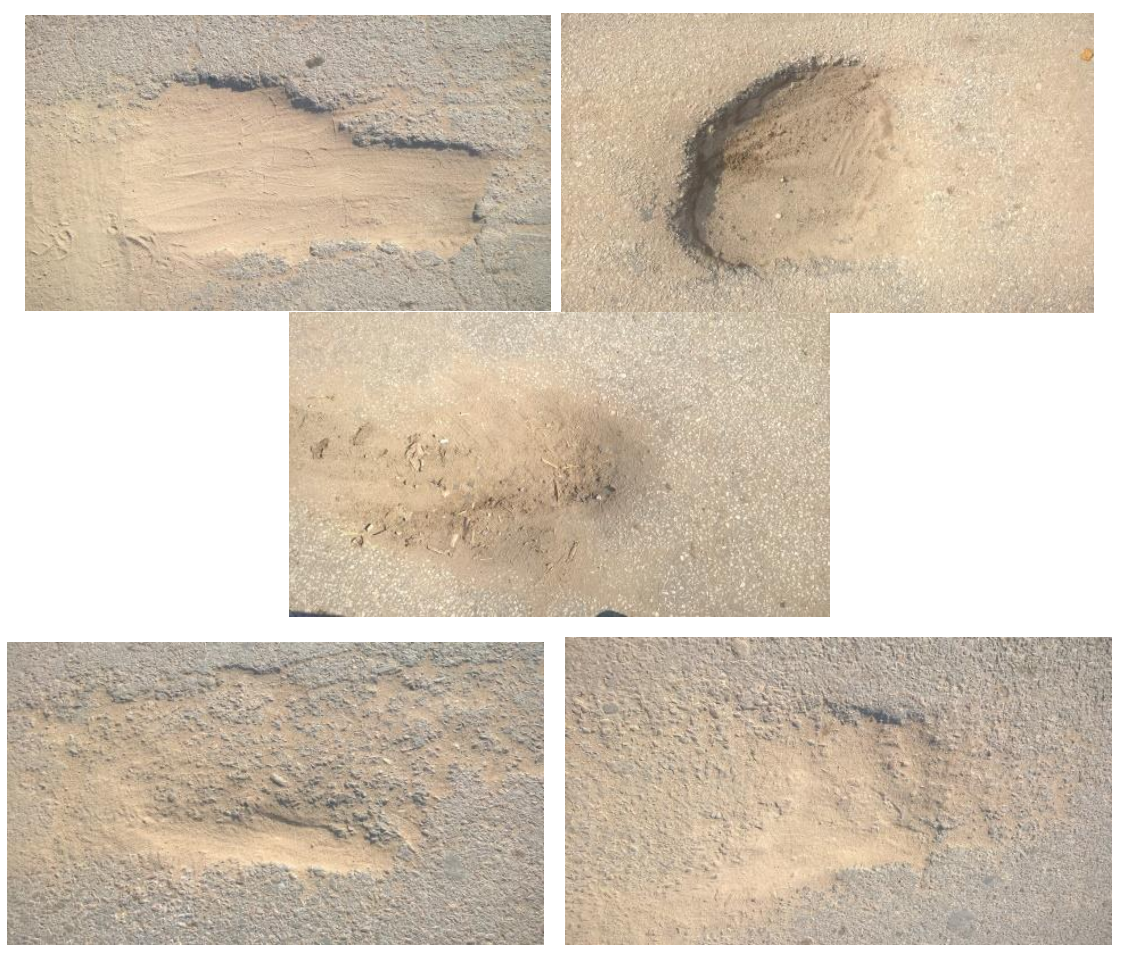

Figure 6 Four detected potholes and one crack

\begin{tabular}{|c|c|c|c|c|c|}
\hline & & Table 1. Digi & l camera calibra & n results & \\
\hline Image No. & $\omega$ in degrees & $\omega$ in degrees & $\kappa$ in degrees & Max. residual error & Max. distortion idealization \\
\hline 1 & 35.809700 & 0.668079 & -178.963342 & & \\
\hline 2 & 19.548483 & -0.488459 & -92.056586 & & \\
\hline 3 & 33.771651 & -1.308848 & 0.339840 & & \\
\hline 4 & 15.263825 & 14.145816 & 5.139530 & & \\
\hline 5 & -1.956560 & -34.192836 & -90.839734 & & \\
\hline 6 & 8.203724 & -14.492386 & 91.765211 & MRE: 1.4301 & $\mathrm{Y}$ axis $=31$ \\
\hline 7 & 8.517045 & 25.590356 & -93.395679 & ORE: $0.278<2.00$ & $\mathrm{X}$ axis $=50$ \\
\hline 8 & 16.687196 & 13.539520 & -3.988177 & reasonable & \\
\hline 9 & 6.199781 & 27.159530 & 88.072455 & & \\
\hline Calibration param & & Value & & Deviation & \\
\hline Focal length $f$ & & $3.622336 \mathrm{~mm}$ & & $0.001 \mathrm{~mm}$ & \\
\hline Xp - principal poi & & $2.251373 \mathrm{~mm}$ & & 7.6e-04 mm & \\
\hline Yp - principal poi & & $1.288946 \mathrm{~mm}$ & & 7.1e-04 mm & \\
\hline $\mathrm{Fx}$ - format of the & dth & $4.538143 \mathrm{~mm}$ & & $2.9 \mathrm{e}-04 \mathrm{~mm}$ & \\
\hline $\mathrm{Fy}$ - format of the & ight & $2.552578 \mathrm{~mm}$ & & $0.147 \mathrm{~mm}$ & \\
\hline$k_{1}$ - distortion 1 & & $-1.298 \mathrm{e}-02$ & & $2.0 \mathrm{e}-04$ & \\
\hline$k_{2}$ - distortion 2 & & $2.857 \mathrm{e}-03$ & & $9.2 \mathrm{e}-05$ & \\
\hline$k_{3}$-radial distortic & & $-1.458 \mathrm{e}-04$ & & $1.3 \mathrm{e}-05$ & \\
\hline$P_{1}$ - tangential dis & ion 1 & $-7.914 \mathrm{e}-05$ & & $2.3 e-05$ & \\
\hline$\underline{P_{2}-\text { tangential dis }}$ & ion 2 & $-2.836 \mathrm{e}-04$ & & $2.2 \mathrm{e}-05$ & \\
\hline
\end{tabular}

\section{RESULTS}

\subsection{Geometric Adjusting of Potholes}

Geometric adjustment is the process that aims to achieve the maximum accuracy of 3D models by using the photogrammetric technique. Hence, each detected object should be identified to simply align/orient the images using the automatic detection mode. 32 Remarkable Automatic Detection (RAD) GCPs were used for creating a Local Coordinate System (LCS). Seven GCPs were used for adjusting X, Y, and Z axis and the other 25 GCPs were used for digital image orientation process. All GCPs were generated using equation [3], and printed on A4 sheets with the same scaled calculated dimensions.

$$
\text { GCP minimum radius }=\frac{7,5 * F u * d}{f * P w}
$$


Where:

$F u$ is the format width of the digital camera sensor,

$d$ is the distance between the camera lens and the farthest expected target,

$f$ is the focal length, and

$P w$ is the total number of pixels in the width of the digital image

The distance between the camera pinhole and the farthest target was assumed $2.00 \mathrm{~m}$ with interior border distance $25.00 \%$ of the GCP radius, as shown in Fig.7. All other parameters were calculated using the calibration process, and the entire radius is $8.51 \mathrm{~mm}$ and the outer radius is $2.51 \mathrm{~cm}$. GCPs were randomly fixed around the targeted pavement potholes and crack, as shown in Fig.8. The other seven GCPs that are used as LCS were adjusted by a Total Station SOKKIA SET 330RK, as shown in Fig.9.

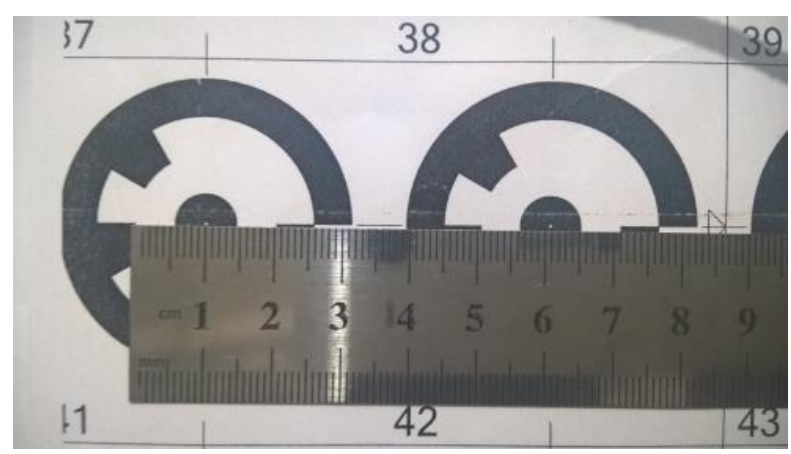

Figure 7 RAD GCPs dimensions

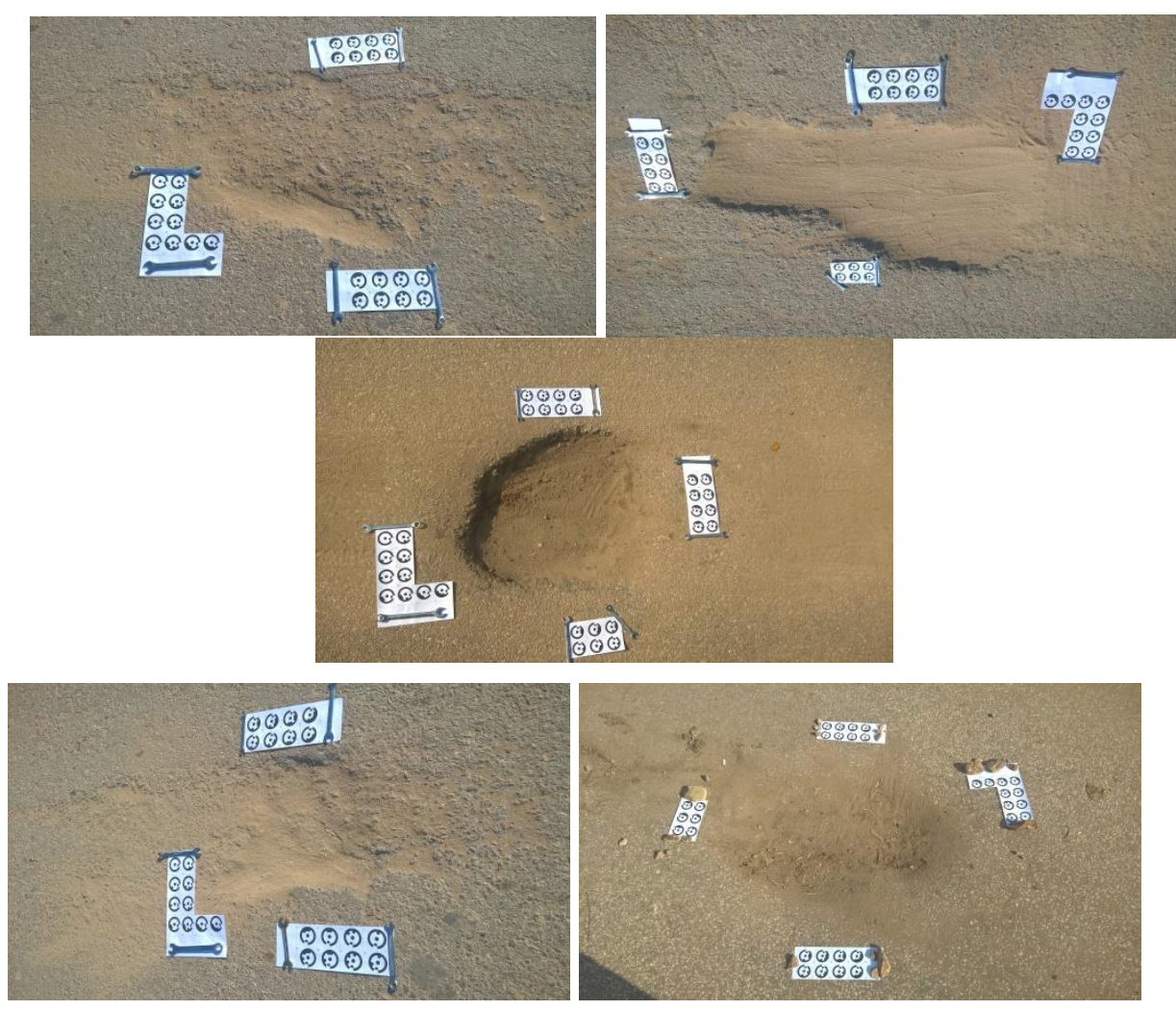

Figure 8 Potholes geometry adjustment 


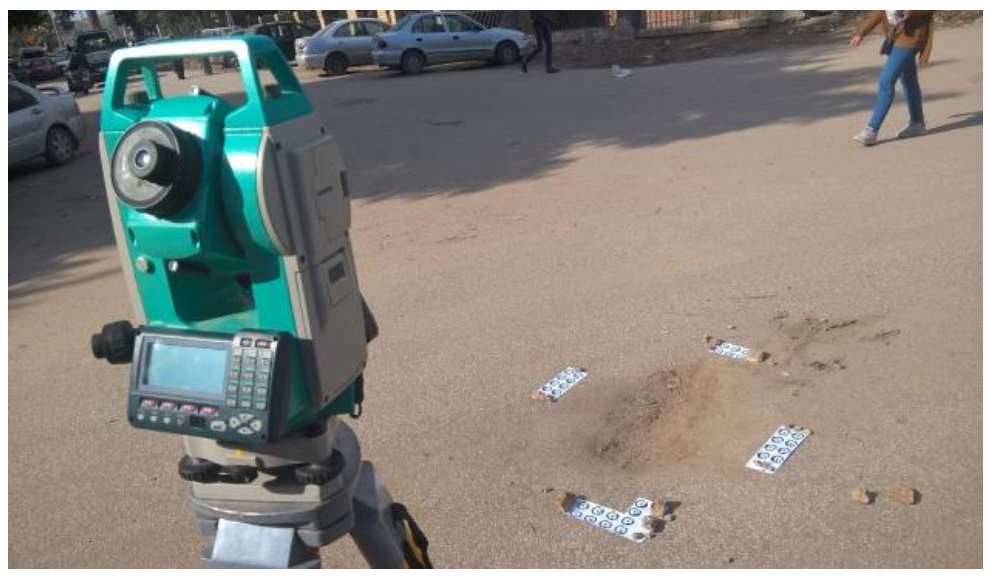

Figure 9 Adjusting GCPs by a Total Station SOKKIA SET 330RK

\subsection{RAD Coded Target Bundle Adjustment and Orientation}

Bundle adjustment is an algorithm that is mainly used, as the final step of the 3D based reconstruction, to optimize the least-square problem of 3D objects view parameters, such as camera intrinsic calibration and the radial distortion in order to achieve the optimum reconstruction with a precise assumption avoiding noise of the observed digital images. It refers to the rays of the light if even nature or artificial, originating from the features of the targeted object to the center of the camera lens [13] as the following equation:

$$
\min _{a_{j}, b_{i}} \sum_{i=1}^{n} \sum_{j=1}^{m} v_{i j} \mathrm{~d}\left(Q\left(a_{j}, b_{i}\right), x_{i j}\right)^{2}
$$

Where:

$Q\left(a_{j}, b_{i}\right)$ is predicted initial projection of a point $i$ on the captured image $j$,

$d(x, y)$ are the presented points of the image on vector $x, y$ interior distance.

Fig. 9, 10, 11 show the GCP adjustment in responding to the camera station as a linear relation.

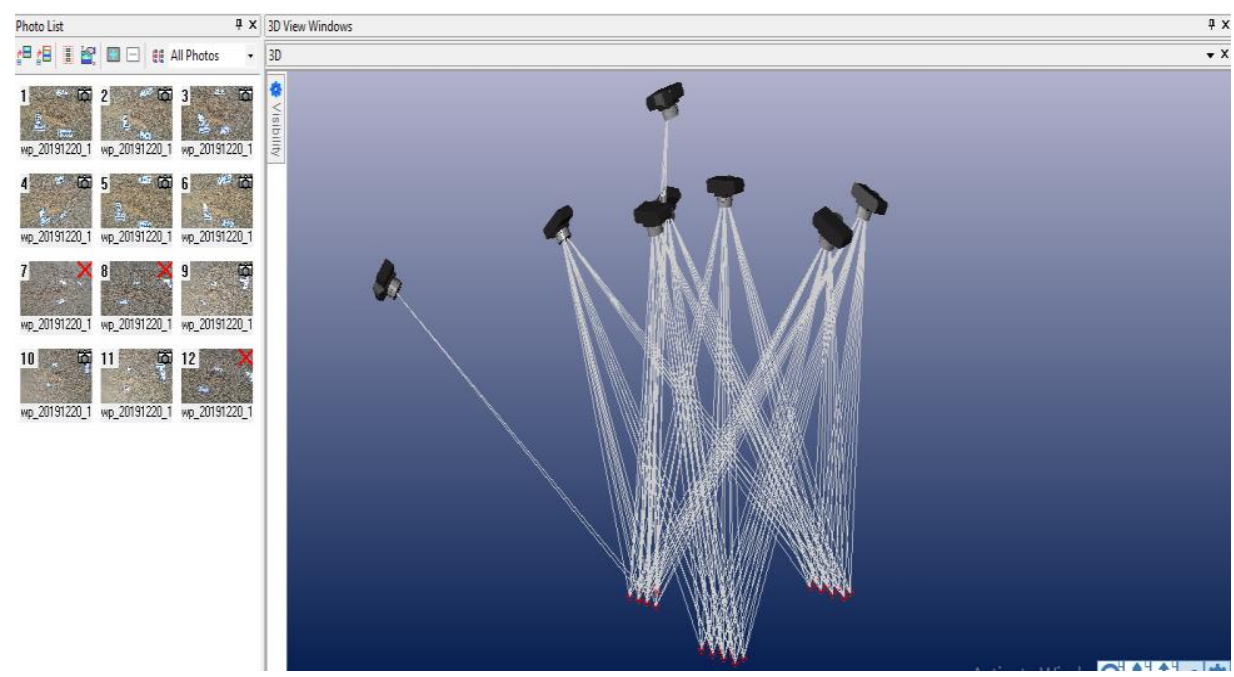

Figure 9 GCP 3D bundle adjustment with low residuals 


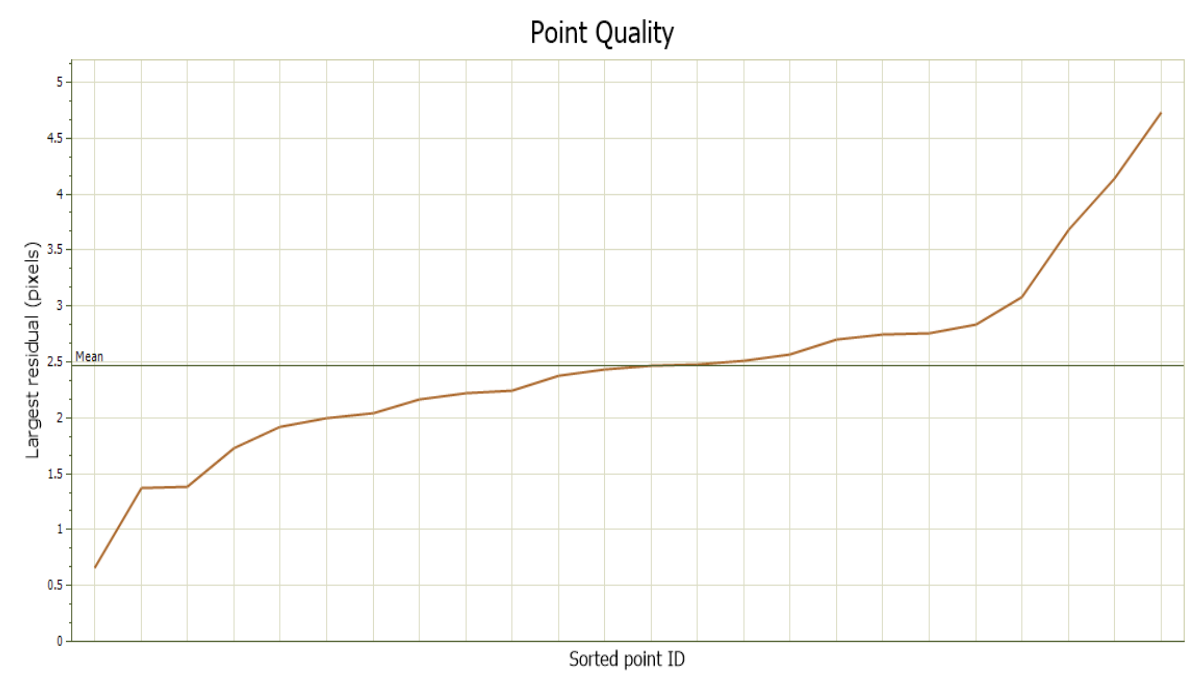

Figure 10.a: GCP maximum residuals of pixels at $\mathrm{Y}$ axis

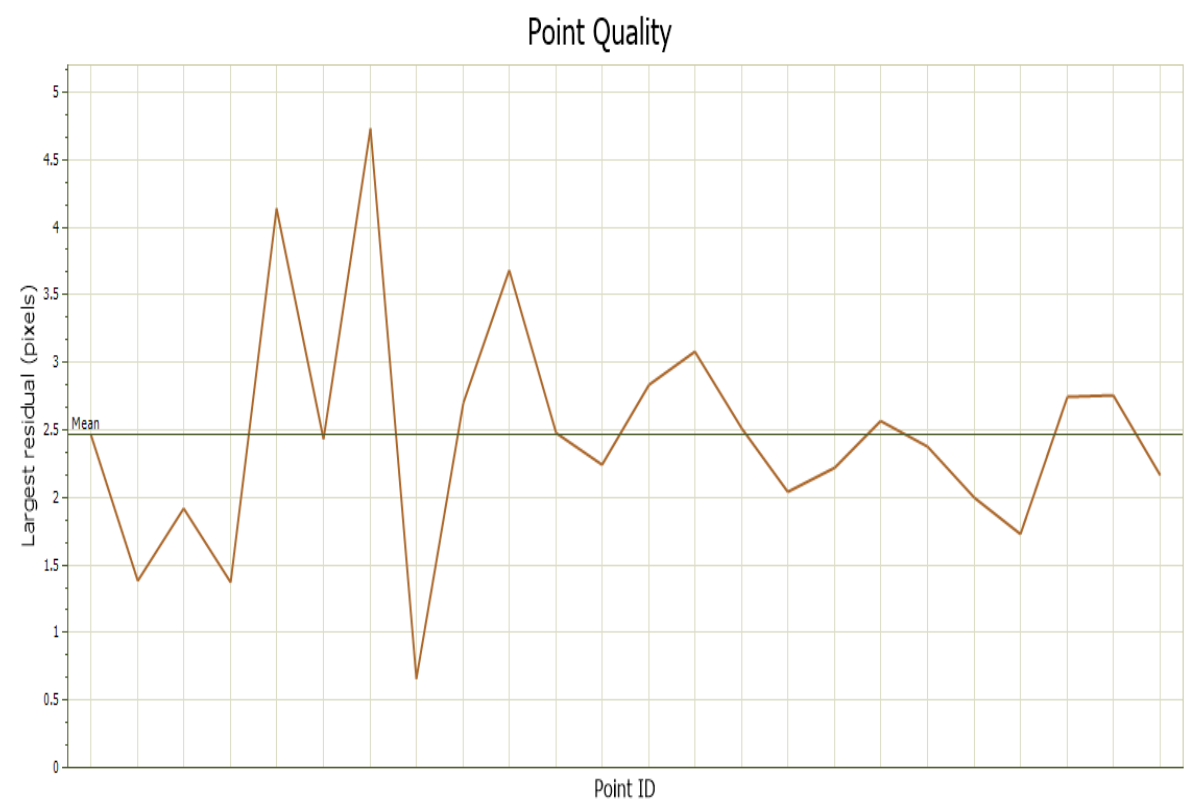

Figure 10.b: GCP maximum residuals of pixels at $\mathrm{X}$ axis

\subsection{Capturing Digital Oriented Images to Create DSMs}

After applying the digital camera calibration process and GCP adjustment, each pavement pothole becomes ready to be digitized through digital imaging. As shown in Fig.9, in order to create the Dense Surface Model with LCS as a first step towards the triangulation process to create the contour maps and Digital Elevation Models (DEM) with color reliefs. Four to eight digital scanning images for each pothole are saved as jpg format with $2365 \mathrm{x} * 4205 \mathrm{y}$ pixels to be processed by the software.

\subsection{Measuring Potholes Dimensions and the Geometry Properties with Discussion}

As a result of all previous phases, the targeted objectives are achieved to prepare the deformations of defined geometric objects. A linear distance is added as a scale pare $=51.00$ $\mathrm{mm}$ between two identified 3D GCPs to make every oriented pixel in the image describes the dimensions in the reality. 
Moreover, the LCS is defined by three GCPs chosen in perpendicular alignment to precisely represent the $\mathrm{X}, \mathrm{Y}, \mathrm{Z}$ axis with the origin point $0,0,0$. The measuring pane shows the geometry properties of the selected object of the 3D space, such as points, distances, areas, volumes of curved surfaces, and angles of camera positions and lines table2. All length measurements executed by identifying the edges on the oriented images by sub-pixel points to represent the dimensions of the object, volumes were generated through the simulation of the pothole on the DSM to create a simulated volume to be calculated by the software.

The depth is calculated by the difference of the bottom sub-pixel point coordinates and the $0.00 \mathrm{Z}$ axis. All measurements were done under residuals that did not exceed 5.00 pixel on images that achieves a high representation of the measurement accuracy.

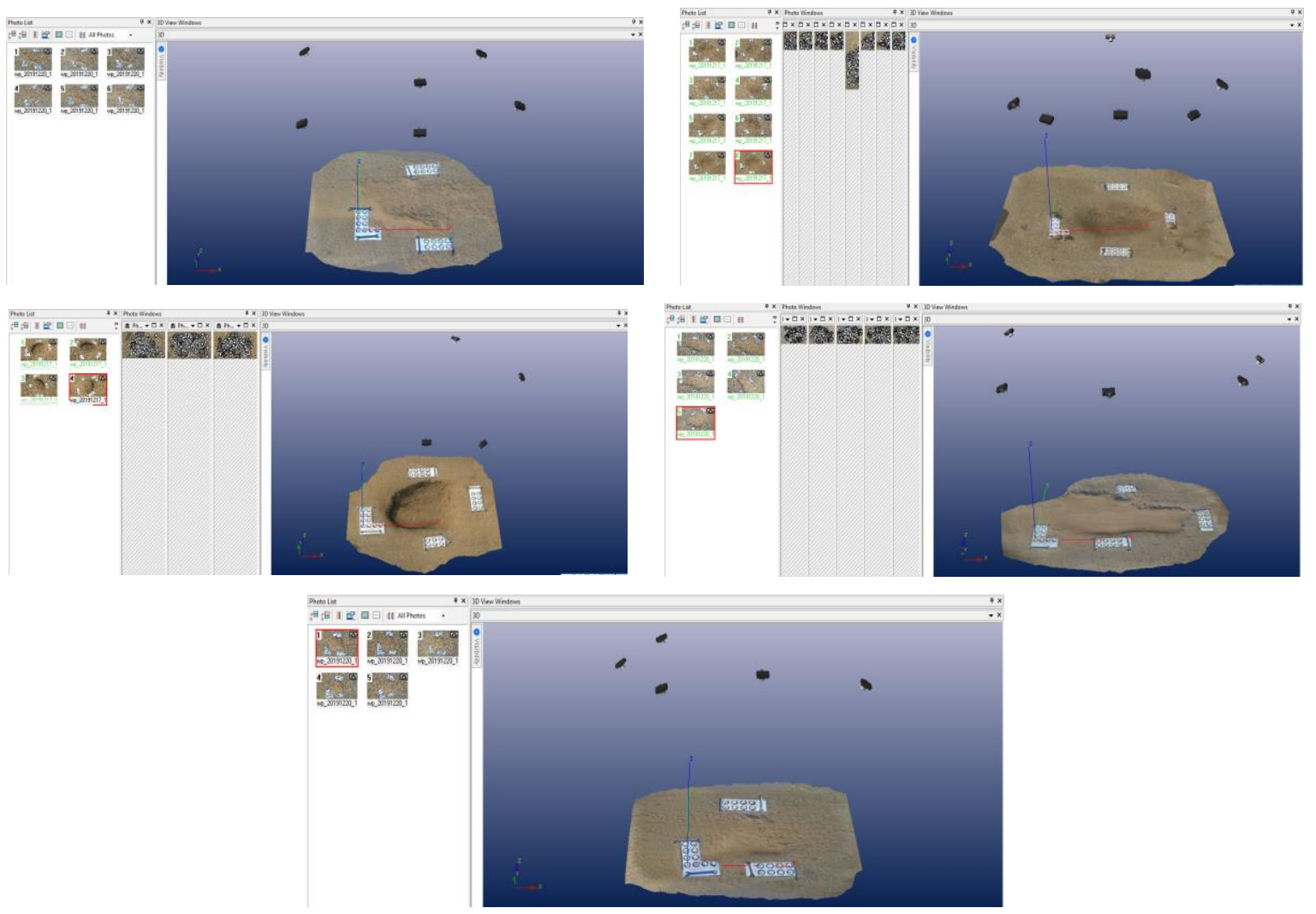

Figure 11 Final triangulated smart 3D DSMs with LCS

\begin{tabular}{|c|c|c|c|c|c|c|c|c|c|}
\hline Type & $\begin{array}{c}\text { Diametei } \\
\text { mm }\end{array}$ & $\begin{array}{c}\text { 1Diameter } \\
\mathrm{mm}\end{array}$ & 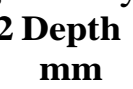 & $\underset{\mathbf{m m}^{3}}{\text { Volume }}$ & $\begin{array}{c}\text { Length } \\
\text { mm }\end{array}$ & $\begin{array}{c}\text { Max. } \\
\text { Residual }\end{array}$ & $\begin{array}{c}\text { Overall } \\
\text { RMS }\end{array}$ & $\begin{array}{l}\text { Point } \\
\text { cloud }\end{array}$ & triangles \\
\hline & & & & & & & \multicolumn{3}{|c|}{ Residual (points) } \\
\hline Pothole & 398.755 & 477.291 & 8.274 & $1,479,580.658$ & & 2.06 & 0.558 & 403564 & 6293 \\
\hline Pothole? & 594.557 & $1,176.934$ & 42.353 & $119,915.100$ & & 2.09 & 0.65 & 238026 & 5736 \\
\hline Pothole? & 469.710 & 715.531 & 81.944 & $10,068,145.474$ & & 2.1 & 0.659 & 284462 & 6463 \\
\hline Pothole & 616.717 & 957.270 & 53.435 & $11,657,039.337$ & & 2.1 & 0.728 & 480185 & 4544 \\
\hline Crack & - & - & - & . & $\begin{array}{l}1,299.921 \\
\mathrm{~mm}\end{array}$ & 2.42 & 0.516 & 365892 & 4794 \\
\hline
\end{tabular}

\section{CONCLUSION}

Applications of the photogrammetric technique became very widespread at all fields of applied sciences. It shows highly accurate representation of geometry properties of features, specially if it possible to adjust the specified object with GCPs to make the final results robust and trusted. By using real-time automatic bundle adjustment and collinearity models, the 
crack and potholes of the pavement were simply and professionally detected by the digital imaging technique, which shows $0.001 \mathrm{~mm}$ with low residuals in range of 1:5 pixels.

\section{REFERENCES}

[1] Rogers, M., (2003). "Highway Engineering”, Blackwell, Oxford,

[2] Nega, A., Nikraz, H., Herath, S., Ghadimi, B. (2015) "Distress Identification, Cost Analysis and pavement temperature prediction for the Long-Term Pavement performance for Western Australia" International journal of Engineering and technology . 7.267-275. 10.7763/IJET.2015.V7.803.

[3] Baskara, S., Yaacob, H., Hainin, M., R., Hassan, S. (2016) "Accident due to pavement condition" A review Journal Teknologi. 78. 10.11113/jt.v78.9494.

[4] Kertész, I., Lovas, T., Barsi, A. (2008) "Photogrammetric pavement detection system" Mechanisms, Modeling, Detection, Testing and Case Histories. 10.1201/9780203882191.ch85.

[5] Luhmann, S., Robson, S., Kyle, I., Harley (2011) "Close Range Photogrammetry Principles, techniques and applications". Whittles Publishing

[6] El-Din Fawzy, H. (2019). Study the accuracy of digital close range photogrammetry technique software as a measuring tool, Alexandria Engineering Journal, Vol. 58, No. 1, 171-179, doi: 10.1016/j.aej.2018.04.004.

[7] Eos Systems, Inc (2016) "PhotoModeler UAS User's Manual”, Vancouverm B.C., Canada

[8] Ouyang, A., Luo, C., Zhou, C. (2010) "Surface Distresses Detection of Pavement Based on Digital Image Processing” 347. 368-375.10.1007/978-3-642-18369-0_42.

[9] Mustaffar, M., Ling, T., C., Puan, O., C., (2008) "Automated Pavement Imaging Program (APIP) For Pavement Cracks Classification and Quantification - A Photogrammetric Approach". Remote Sensing and Spatial Information Sciences. 2008; 37:B4.

[10] El-Din Fawzy, H. (2015) "The Accuracy of Mobile Phone Camera Instead of High Resolution Camera In Digital Close Range Photogrammetry". International Journal of Civil Engineering \& Technology (IJCIET), Volume 6, Issue 1, pp. 76-85.

[11] Abdel-Aziz, Y. I. and Karara, H. M., (1974) “Accuracy Aspects of Non-Metric Imageries" University of Illinois, Urbana, Illinois 61801, pp. 1107-1117.

[12] Jason P. de Villiers a, b, F. Wilhelm Leuschnerb et al, (2008) Centi-pixel accurate realtime inverse distortion correction. International Symposium on Opt mechatronic Technologies, California, United States

[13] Manolis I., A., Antonis A. (2009) "A software package for generic sparse bundle adjustment , ACM Transactions on Mathematical Software (TOMS), v.36 n.1, p.1-30. 